\title{
Enhancing Engineering Management Courses with Global Market Concerned Projects and Case Studies
}

\section{Dr. S. Gary Teng, The University of North Carolina at Charlotte}

Dr. S. Gary Teng is Professor of Systems Engineering \& Engineering Management and Director of Center for Lean Logistics and Engineered Systems at the University of North Carolina at Charlotte. He holds a P.E. license in the State of Wisconsin. His research interests are in engineering system design, analysis and management, supply chain management, lean systems, and risk management. Dr. Teng received the Bernard R. Sarchet Award in the Engineering Management Division of ASEE in June 2012 for his accomplishment in engineering management education. 


\title{
Enhancing Engineering Management Courses with Global Market Concerned Projects and Case Studies
}

\begin{abstract}
With the changing global business environment, engineering managers and executives need to deal with the competition related business and engineering issues constantly. They need to have a vision while working on their management and engineering tasks and making various decisions. The objective of this paper is to discuss the ways to educate and train engineering management students to sharpen their abilities in making good decisions and creating a vision in a competitive environment. This paper will also discuss the effect of embedding the consideration of marketing, branding, value creation, innovation, global location characteristics, policies related engineering issues, and competition into class case studies and projects. The purpose is to teach engineering management students how to make good decisions with a broader business and engineering vision while managing engineering and business operations.

In this research, the examples discussed include a term case study assigned to students to develop an investment strategy for a top 5 brand value company to increase market share in the next top global smartphone market, a term project to design and develop a transparent factory in the US locations to promote Made-in-USA approach, and a term project to consider moving existing engineering and manufacturing activities in a top smart phone company from abroad back to the US locations for following the Made-in-USA trend. The purpose of using these term case studies and projects in engineering management related classes is to lead students to realize the importance of value creation, market dominance, understanding of competition, innovative approaches, good handling of global economy and policies related issues for successful engineering operations and decision-making.
\end{abstract}

\section{Introduction}

Dealing with engineering operations and projects, current and future engineering managers and/or executives need to consider broader global supply chain and market competition issues while making various types of decisions to manage their engineering and business operations. It becomes necessary for engineering and engineering management educators to teach students in a way to obtain the ability and capability to consider the effects of global supply chain influence, international market competition, the constraints caused by regional concerns, the issues triggered by constant changes of global business and political environment for making effective engineering decisions.

The issue here is how to insert the required contents into existing engineering management curriculum or courses to establish students' capability in dealing with the global business/engineering issues while making engineering decisions. The objective of this paper is to provide an approach in using term projects and case studies to offer engineering/engineering management students the knowledge and awareness of the global market issues and constraints on various engineering/business operations, so they would take more comprehensive evaluation of all factors while making engineering decisions. 
The ultimate purpose of this paper is to discuss the ways to educate and train engineering/engineering management students with less required resource or change in the existing curriculum to sharpen their abilities in making good decisions and creating a global vision in a competitive environment.

The result of this paper provides a brief discussion of the influence of implementing this type of assignments in engineering management related classes, how students responded to this type of requirements while doing their assignment, and how they presented their work results at the end of this course term. This discussion provides an example for engineering management educators using similar approach to offer their students the experience in dealing with the changing global business/engineering environment.

\section{Research Objectives}

The main objective of this paper is to discuss the different ways to educate and train engineering management students to improve their abilities in effective decision-making and vision creation in a competitive environment. How to use an effortless way to achieve this objective in class offerings would be another purpose of this research. Using term project and term case study assignments is the approach being used in reaching the desired goal without requiring too much extra efforts from the faculty.

The purpose of using term case study and term project assignments in engineering management related classes is to lead students to recognize the importance of value creation, market dominance, understanding of competition, innovative approaches, good handling of global economy and policies related issues for successful engineering operations and decision-making.

\section{The Approach}

The approach is to use case studies and projects to offer students the experience and concepts involving the considerations of global business/engineering issues for effective engineering decision-making. In the arrangement of the classes, term case studies or term projects are used to enhance the teaching of concepts and implementations with the addition of issues related to business, strategy, value, market, and globalization.

Figure 1 shows a simple diagram representing the use of case discussions and video clips in lectures and term case studies and term projects as a semester-long assignment.

In this research, the examples of projects and case studies include three different areas. The first area is a semester-long case study assigned to students to develop an investment strategy for a top 5 brand value company to increase its global market share. In additional to that, the case study was revised to ask students to work on the increase of the market share in the next top global smartphone market. The second area is a semester-long project for students to design and develop a transparent factory in the US locations to promote the Made-in-USA approach. The third area is a term project to consider moving existing engineering and manufacturing activities in a top smart phone company from abroad back to the US locations for following the Made-inUSA trend. 


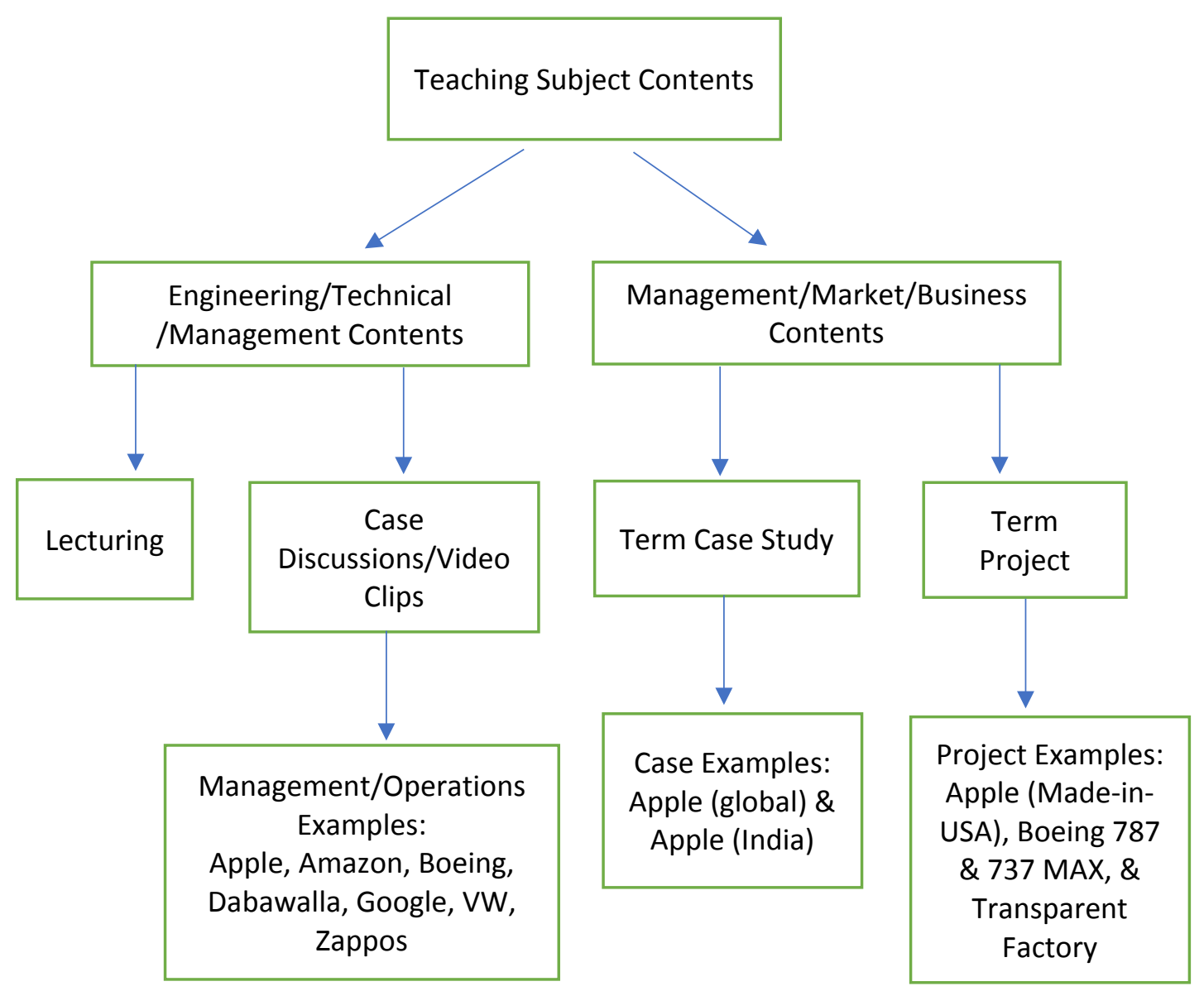

Figure 1. The Approach Using Case Studies and Projects

The purpose of using these term case studies and projects is to emphasize the importance of the issues that are associated with engineering operations but are often ignored by the technical personnel. These issues include the creation of value in engineering operations, the operation profit due to market dominance, the dynamic business/engineering environment due to competition, the criticality of innovation for successful engineering operations, and the effective handling of global economy and policies related issues for successful engineering operations and decision-making.

\section{The Discussion of Cases}

In this approach, offering lectures to teach technical and management concepts with real case discussions and some video clips can greatly boost students' interest in the concepts and can also effectively embed the good practice principles and the needed attention on broader global factors in engineering decision-making process into their thought process.

The cases discussed in several engineering management/systems engineering graduate and undergraduate classes comprise cases like Apple’s supply chain operations and Apple Store 
operations, Boeing's 787 and 737MAX operations [1], VW's transparent factory approach [2], Amazon's management approach, Google's implementation of OKRs, Dabawalla's efficient operations [3], Zappos' Holacracy approach [4], and some examples of manufacturing operations in China based industry with US connections.

The case discussions also provide students some general guidelines and ideas about what to achieve in a successful case study or project that they are working on.

\title{
The Work on a Term Case Study
}

In a sophomore engineering economic analysis class, students are required to work on a semester-long case study to get better understanding of economics related engineering decisionmaking issues that involves value creation, product positioning, market competition, and technology innovation. The purpose of this assignment is to let students recognize that making engineering decisions involves not only the assessment of technical and economic factors but also the appraisal of value increase, product's market dominance, and the influence of global business/engineering environment.

The following statements show the main requirement for a case study assignment.

\begin{abstract}
The case study work should include the case of analyzing the capital investment strategy in the next five-year period for Apple, Inc. to enhance its design, production, future new product deployment, and market dominance. The expected budget is 50 million dollars of the present-day value. The case study needs to discuss what the strategy should be, how much to invest in each of the next five years, and what the expected return would be. Assume that your team is one of the upper management teams in Apple and oversees developing alternative(s) for future capital investment decisions in the company. Your team needs to sell your capital investment strategy to the Apple executive team. This study should consider from at least two perspectives: the value perspective (return or profit) for Apple business and the market perspective for Apple to be at least one step ahead of its competitors. Assume that the annual interest rate in the market available to Apple is $6 \%$ per year.
\end{abstract}

This case has been assigned to engineering students for a couple of years with some minor variation in allocated budget. The assignment leads students to investigate Apple product lines, business strategy, value allocation, market positioning strategy and associated issues for economic/investment strategy. This case study expands students' view on engineering decisionmaking with the consideration of higher level factors and strategy. The benefit of this approach is to change the thought process of students and elevate their viewpoints to a higher and more comprehensive level.

There are positive feedbacks from students regarding the work on the case study. The real benefit comes from students' reflection on different decision-making situations during class discussions and case study presentations. They have embrace more elevated level of economic, technical, and business issues in their discussions. However, there was one issue that caused the faculty to consider further improvement of the case study. This issue was the lack of global 
perspective in the investment strategies students have developed. Most of the case work presented by students were US centric in nature even though the instructing faculty emphasized the importance of global perspectives at the beginning of the semester.

To overcome this issue, the case study assignment was changed to embrace the world's next biggest smart phone market - India [5]. The following statements show the main requirements for the revised case study assignment.

The case study work should include the case of analyzing the capital investment strategy in the next three-year period for Apple, Inc. to enhance its design, production, future new product deployment, and market dominance in the second largest smartphone market in the world - India. The expected budget is 20 million dollars of the present-day value. The case study needs to discuss what the strategy should be, how much to invest in each of the next three years, and what the expected return would be. Assume that your team is one of the upper management teams in Apple and oversees developing alternative(s) for future capital investment decisions in the company. Your team needs to sell your capital investment strategy to the Apple executive team. This study should consider from at least two perspectives: the value perspective (return or profit) for Apple business and the market perspective for Apple to be at least one step ahead of its competitors in the Indian market. Your team also needs to consider the current Made-in America trend promoted by President Trump to move manufacturing activities back to the US. Assume that the annual interest rate in the market available to Apple is $6 \%$ per year.

This changed focus on India market requirement forced students to deal with foreign market issues in addition to all other considerations. This change opened students' US centric perspective in their case study and required them to investigate the factors associated with the market in India. It also provided students another perspective in the case study, Apple's weak presence in the India market.

With the addition of India market requirement, the case study created students' interest in global issues. However, there was one issue occurred in the approaches developed by most students who spent too much efforts on how to reduce iPhone manufacturing costs to make iPhone price competitive in the India market. This way of thinking pushed students to the corner of cost reduction instead of value creation. With the guidance to students regarding balancing value creation and cost reduction at the beginning of the case study in the next class offering, students were able to jump out of the cost reduction box, and worked on a strategy not just considering one Apple product, iPhone. This alteration in perspective generated more creative case study results from the students.

\section{The Work on a Term Project}

To achieve the desired outcome, a semester-long project is another valuable tool for educating students and training them on dealing with various engineering/business related issues in systems, engineering, and business operations. The key is to find the right types of projects for 
students to work on, so students can embrace most factors associated with current dynamic engineering, business, and supply chain environment.

The project assignments mentioned here were required in some of the graduate and undergraduate courses in project management, advanced project management, and systems engineering concepts courses. The following three separate groups of statements demonstrate the three types of projects being assigned to students in the above-mentioned courses.

\section{Project Type I:}

This term project involves applying project management principles to the term project. It involves the planning and development of a capital investment strategy in the next three-year period for Apple, Inc. to follow its new strategy in building new manufacturing capability in the United States to enhance its design, production, future new product deployment, and market dominance in the US market and support the promotion of Made-in-USA national manufacturing strategy.

The expected investment budget is 800 million dollars to 1 billion dollars of the present-day value. This project needs to consider the issues of moving manufacturing activities from Asia to the US, including all the supply chain \& supplier issues. The project needs to provide what the strategy should be, how much to invest in each of the next three years, how to establish the manufacturing capability in the US efficiently, how to convince suppliers to move their manufacturing activities to the US, and what the expected return would be by implementing the proposed strategy. Assume that your team is one of the upper management teams in Apple and oversees developing alternative(s) for future capital investment decisions in the company. Your team needs to sell your capital investment strategy to the Apple executive team. This project should consider from at least two perspectives: the value perspective (return or profit) for Apple business and the market perspective for Apple to be at least one step ahead of its competitors in the global market. Assume that the annual interest rate in the market available to Apple is $5 \%$ per year.

\section{Project Type II:}

This term project involves applying project management principles to the term project. It also involves the planning and development of a plan for building a transparent plant in the Charlotte area for a type of product(s) by each team's own selection.

One of the purposes for building a transparent plant is to follow President Trump's strategy in building new manufacturing capability in the United States. To move manufacturing capability back to the US, companies need to increase the value of manufacturing operations to compensate higher labor related manufacturing costs in US manufacturing facilities. Transparent plant approach 
provides added values to the manufacturing operations in the US. This project is to enhance US companies' design, production, future new product deployment, and market dominance in the US market and support the promotion of Made-in-USA national manufacturing strategy.

Some video clips for showing Volkswagen's transparent factory in Dresden, Germany are good information sources for the similar work. The project work should include the consideration of project management activities in integrating various system elements and/or sub-system elements for future efficient plant operations in a specified region. The emphases can be from different perspectives of the design, such as from the perspective of the support of local region's supplier network, the perspective of local government's plan in improving local infrastructure to support the plant's operations, or the perspective of the activities in designing the factory in a specified area.

\section{Project Type III:}

This term project involves the study and the application of systems engineering process to the development or improvement of Boeing 787 Dreamliner and the new upgraded version of 737 (737MAX), especially the new 737MAX-10 model development, manufacturing, quality, supply chain, and marketing processes with the integration of its system and sub-system components. This project results will be evaluated based on the technical effort and contribution on the selected approach.

\section{Objective:}

The objective of this project work is to demonstrate:

- an understanding of the systems engineering approach and systems integration issues,

- knowledge of the primary issues in Boeing 787 Dreamliner and the new upgraded version of 737 (737MAX), especially the new 737MAX-10 model development manufacturing, quality, supply chain, and marketing processes,

- the ability to use an efficient procedure for 787 Dreamliner and the new upgraded version of 737 (737MAX), especially the new 737MAX-10 model development, manufacturing, quality, supply chain management, and marketing,

- an ability to communicate in systems engineering terminology, and

- the ability to deal with global engineering, systems, and supply chain issues.

\section{Project Contents:}

This project work should include problem definition, literature review, methodology and research development and implementation, and analysis and evaluation of the research/implementation results. This project can be a research in systems, supply chain, or management related issues in Boeing 787 Dreamliner and the new upgraded version of 737 (737MAX) development, manufacturing, quality, supply chain, and marketing processes, a design or 
improvement of a specific system or subsystem issue, or a development of a

new system process and its related system issues.

For all these project assignments, students need to consider major factors in the current changing engineering/business environment while working on their projects. On top of the technical related issues, students need to embrace the factors of value creation, market dominance, systems effectiveness, and the economic and political consideration in their project work. In addition, students gain knowledge on effective engineering/business practices since they need to explore the business/engineering operations of these top technology/engineering companies when they start their project work.

In all project work, students need to do three team project presentations and submit three project reports, including proposal, progress report, and final report. Among these presentations, students are required to evaluate other project teams' presentations based on a set of specified criteria. Along with the presentation evaluation, each student also needs to select the best three teams and does a peer evaluation.

With the voting for the top three teams in each of the presentations, the term project environment has embrace a competitive environment with a competition among all the project teams. Each team needs to work on convincing other classmates to vote for the team as one of the top three teams at the end of each report presentation. This process offers students the opportunity to learn how to offer their competitors enough project information to impress them to earn their votes and, at the same time, not to offer enough information for the competing teams to learn from the team's work to compete with the team.

\section{Example of the Assessment Results}

Two ways are used to assess the effectiveness of the approach. The first way is to evaluate a project team's project product selection and the contents of the proposal, progress report and final report. The second way is to evaluate an end-of-semester survey results completed by the students. Figure 2 and Table 1 show the Apple investment in India case study survey and its results.

From the survey results, the top three perspectives for students to work on the India market case include Marketing, Branding, and Financial Feasibility. If they work on the case for the US market, the top three perspectives would be Production/Manufacturing Costs, Factory Location, and Market Competition Issues. When students work on the India market case, their approach and thought process are more pointing to the market and business concerns. Their decisionmaking process moves toward higher-level business strategy issues. When the case is to deal with the US market, their thought process moves toward more traditional concerns in costs for manufacturing and production processes and factory operations.

A discussion of the effects of using transparent factory project in classes can be found in the previous work by Teng [6] that is concentrated on the students' transparent factory project work. 


\title{
SEGR 2106 Apple Investment in India Case Study Survey
}

\author{
While you are working on your case study, you and your team's perspectives in working on this case \\ study are pointing toward (select the critical ones):

$\begin{array}{lll}\square \text { Branding } & \square \text { Marketing } & \square \text { Production/Manufacturing Costs } \\ \square \text { Logistics Operations } & \square \text { Factory Location } & \square \text { Local Economic Development } \\ \square \text { Global Supply Chain Issues } & \square \text { Financial Feasibility } & \square \text { Business Development } \\ \square \text { Market Competition Issues } & \square \text { Regional Economics Issues } & \square \text { Global Political issues } \\ \square \text { Support Operations } & \square \text { Product Design Issues } & \square \text { Global Business Issues }\end{array}$

If this project is a US market case study, you and your team's perspectives in working on the project would be pointing toward (select the critical ones):

$\begin{array}{lll}\square \text { Branding } & \square \text { Marketing } & \square \text { Production/Manufacturing Costs } \\ \square \text { Logistics Operations } & \square \text { Factory Location } & \square \text { Local Economic Development } \\ \square \text { Global Supply Chain Issues } & \square \text { Financial Feasibility } & \square \text { Business Development } \\ \square \text { Market Competition Issues } & \square \text { Regional Economics Issues } & \square \text { Global Political issues } \\ \square \text { Support Operations } & \square \text { Product Design Issues } & \square \text { Global Business Issues }\end{array}$

In your opinion, is there any difference in approach for you to work on a US market case study and an India market case study?

$\square$ Yes $\quad \square$ No

If there is a difference in approach, what is/are the difference(s)?

Which type of case study, a US market case study or a global market (like India) case study, provides you broader perspectives in economics issues, investment strategy concerns, and business and management issues?

$\square$ US Market Case Study $\quad \square$ Global Market Case Study $\quad \square$ None

Name:

Figure 2. Apple Investment in India Case Study Survey 


\begin{tabular}{|l|c|c|}
\hline \multicolumn{1}{|c|}{ Perspective/Market Location } & India Market & US Market \\
\hline Branding & $\mathbf{1 8}$ & 18 \\
\hline Marketing & $\mathbf{3 0}$ & 20 \\
\hline Production/Manufacturing Costs & 14 & $\mathbf{2 7}$ \\
\hline Logistics Operations & 8 & 12 \\
\hline Factory Location & 12 & $\mathbf{2 2}$ \\
\hline Local Economic Development & 14 & 9 \\
\hline Global Supply Chain Issues & 5 & 9 \\
\hline Financial Feasibility & $\mathbf{1 8}$ & 12 \\
\hline Business Development & 13 & 15 \\
\hline Market Competition Issues & 13 & $\mathbf{2 1}$ \\
\hline Regional Economics Issues & 15 & 11 \\
\hline Global Political Issues & 11 & 8 \\
\hline Support Operations & 7 & 4 \\
\hline Product Design Issues & 6 & 12 \\
\hline Global Business Issues & 10 & 4 \\
\hline
\end{tabular}

Table 1. Perspectives for Apple Investment in India Case Study

\section{The Effect of the Case Study and the Project}

With the work on the case studies and projects, students have changed their attitude in their work toward global issues and engineering and business decision-making. They have raised their awareness on global market condition changes, the constraints of global engineering operations, the potential issues caused by global competition, the long-term risks, and the potential longterm value for their engineering operations.

Students also learned to present their results based on the values their projects have generated with the consideration of market and business constraints, risks, opportunities, and global issues. The key is that they have gone beyond a localized system/operation perspective in their project work. It is very critical to the success of current and future project work.

This work also brings their interest in global operations and the current and future trends of industry and market. One example is that most students who finished the Apple investment strategy case study would watch the Apple Special Event in September of each year and discuss the issues associated with the newly announced devices with their peers and faculty.

\section{Conclusion}

This paper discussed the ways to educate and train engineering/engineering management students to hone their abilities in making effective decisions and creating a more valuable vision in a competitive environment using case study and project assignments. The discussions also 
include the effect of embedding the consideration of marketing, branding, value creation, innovation, global location characteristics, policies related engineering issues, and market competition into class case studies and projects. The ultimate purpose of these case studies and projects is to teach engineering management students effectively on how to make good decisions with a broader business and engineering vision while managing engineering and business operations.

In this research, the examples discussed include a term case study assigned to students to develop an investment strategy for the next biggest global smartphone market, a term project to design and develop a transparent factory in the US locations to promote Made-in-USA approach, and a term project to consider moving existing engineering and manufacturing activities from abroad back to the US locations for the Made-in-USA trend.

The results of the case study and project work offered students the knowledge and experience on the importance of value creation, market dominance, understanding of competition, innovative approaches, good handling of global economy and policies related issues for successful engineering operations and decision-making. The approach presented in this paper can be easily duplicated in various engineering/engineering management courses.

\section{References}

1. Ben Mutzabaugh, "Boeing Delivers its First 737 MAX,” USA TODAY, May 2017.

2. Volkswagen, "The Transparent Factory - A Glass Factory Creating Transparent Excellence," Volkswagen UK, http://www.volkswagen.co.uk/about-us/company/factories/glass-factory.

3. "DabbaWalas - Amazing Meal Delivery in India (Dabbawalas)," https://www.youtube.com/watch?v=fTkGDXRnR9I.

4. “Zappos Embraces "Holacracy",” https://www.youtube.com/watch?v=RnQkP691a_s.

5. Sumit Passary, "India is Now Second Largest Smartphone Market in the World," Tech Times, February 2016, http://www.techtimes.com/articles/130392/20160204/india-is-nowsecond-largest-smartphone-market-in-the-world.htm.

6. S. Teng, "Using Transparent Factory Design Projects to Enhance Engineering Management Teaching," Proc. of 2015 ASEE Annual Conference, Seattle, Washington, June 2015. 